\title{
PARAPLEGIA AFTER SURGERY OF THE THORACIC ESOPHAGUS
}

\author{
Tommaso Claudio Mineo, MD, Benedetto Cristino, MD, and Vincenzo Ambrogi, MD, Rome, Italy
}

Paraplegia after thoracic surgery is an uncommon complication, ${ }^{1-4}$ and it is even more uncommon after surgery of the thoracic esophagus. Herein we describe 2 cases that occurred in our experience.

\section{Clinical summaries}

CASE 1. A 72-year-old man was admitted for the treatment of worsening dysphagia. Barium swallow and esophagogastroscopy revealed a mass $31 \mathrm{~cm}$ from the incisors, and the biopsy results showed squamous carcinoma. There was no evidence of locoregional spread or metastases at endosonography and computed tomographic scan. The examination revealed a $3.5-\mathrm{cm}$ abdominal aortic aneurysm and diffuse signs of atherosclerosis. The patient underwent an intrathoracic esophagogastroplasty through a left thoracophrenolaparotomy. Tumor dissection necessitated the interruption of some vessels. No perigastric or mediastinal lymph nodes appeared to be involved. The early postoperative period was uneventful apart from a mild paresthesia of the lower limbs. After 24 hours he suddenly became unable to move his legs. Reflexes were totally absent below the T10-11 level. Multiorgan failure progressively developed and he died 7 days later. Postmortem examination showed a normal appearance of the anastomosis and of the tubulized stomach. An ischemic trait of the spinal cord at the T12-L1 level was also evident.

CASE 2. A 58-year-old man was referred for treatment of a 5$\mathrm{mm}$ vegetating lesion that resulted in an infiltrating squamous cell carcinoma situated $27 \mathrm{~cm}$ from the upper incisors. Endosonography and computed tomographic scan did not show local infiltration or metastases. Esophagectomy was accomplished by blunt dissection, and tubulized stomach was anastomosed at the cervical level. No difficulties were found in gastric preparation and esophageal dissection. The early postoperative period was normal. After 38 hours, the patient began exhibiting a progressive sensory and motor deficit of the lower limbs originating at T6-T7. Magnetic resonance imaging showed an ischemic lesion of the spinal cord and excluded external compression. Apart from neurologic conditions, recovery was rapid. Despite continued medical and rehabilitative treatment, neurologic status was unchanged at 2 years.

From the Thoracic Surgery Tor Vergata University, Rome, Italy.

This study has been carried out within the research fellowship program "Dottorato di Ricerca in Oncologia Toracica," appointed by Tor Vergata University of Rome.

Received for publication May 11, 1998; accepted for publication May 28, 1998.

Address for reprints: Tommaso Claudio Mineo, MD, Chirurgia Toracica, Tor Vergata University, Ospedale S. Eugenio, P.le Umanesimo, 10, 00144 Rome, Italy.

J Thorac Cardiovasc Surg 1998;116:653

Copyright $\odot 1998$ by Mosby, Inc.

0022-5223/98 \$5.00+ $0 \quad \mathbf{1 2 / 5 4 / 9 2 1 4 6}$
Discussion. Paraplegia after surgery of the thoracoabdominal aorta is a widely known phenomenon, but it is very uncommon after pulmonary, tracheal, or pleural surgery ${ }^{1-4}$ and even less frequent after esophageal surgery. To our knowledge, the sole existing report is from Merlier and Thevenet, ${ }^{4}$ who described a case of medullar injury resulting from a Nissen fundoplication that had been tailored through a left thoracotomy: the damage was probably related to the interruption of branches from the intercostal arteries supplying the spinal cord.

We have hypothesized the aforementioned mechanism in our patients. In the first case, the removal of the bulky esophageal tumor in the paravertebral region is likely to have entailed the direct or indirect interruption of an artery supplying a wide territory of the spinal cord. The consequences were worsened by the generalized status of atherosclerosis. For the second case, a reasonable hypothesis is much more difficult to formulate. Despite our vast experience with transhiatal esophagectomy, we had never faced this complication before and we did not encounter it on review of important reports. ${ }^{5}$ The possibility of a common vessel supplying both the esophagus and the spinal cord remains the most probable cause. These vessels might be interrupted during blunt dissection.

Interruption of intercostal branches during esophageal dissection rarely produces devastating effects by itself. However, it may precipitate subischemic conditions, such as a hypotrophic or atherosclerotic Adamkiewicz artery. ${ }^{3}$ On this basis, whenever we plan esophageal dissection in elderly patients with generalized atherosclerosis, we suggest an arteriographic study of the medullar supply. We thereby ascertain the presence and the origin of the Adamkiewicz artery. Nevertheless, paraplegia remains a nearly unpredictable occurrence.

In conclusion, medullar lesions after surgery of the thoracic esophagus are uncommon and are mainly due to ischemic damage. The surgeon should be aware of this devastating complication to avoid risky maneuvers.

\section{REFERENCES}

1. Batellier J, Wihlm JM, Morand G, Witz JP. Paraplegie par hematome extra-dural rachidien apres lobectomie elarge pour cancer. Ann Chir 1989;43:210-4.

2. Short DH. Paraplegia associated with the use of oxidized cellulose in posterolateral thoracotomy incisions. Ann Thorac Surg 1990;50:288-90.

3. Attar S, Hankins RJ, Turney ZP, Krasna JM, McLaughlin SG. Paraplegia after thoracotomy: report of five cases and review of the literature. Ann Thorac Surg 1995;59:1410-6.

4. Merlier M, Thevenet A. Table ronde sur les complications medullaires de la chirurgie du thorax et de l'aorte et de ses branches. Ann Chir Thorac Cardiovasc 1980;34:521-55.

5. Orringer MB. Transhiatal esophagectomy without thoracotomy for carcinoma of the thoracic esophagus. Ann Surg 1984;200:282-8. 